\title{
Corrigendum
}

\section{Corrigendum to "Prognostic Effect of Long Noncoding RNA NEAT1 Expression Depends on p53 Mutation Status in Cancer"}

\author{
Masashi Idogawa $\mathbb{D}^{1,2}{ }^{1,2}$ Hiroshi Nakase, ${ }^{2}$ Yasushi Sasaki, ${ }^{3}$ and Takashi Tokino $\mathbb{D}^{1}$ \\ ${ }^{1}$ Department of Medical Genome Sciences, Research Institute for Frontier Medicine, \\ Sapporo Medical University School of Medicine, Japan \\ ${ }^{2}$ Department of Gastroenterology and Hepatology, Sapporo Medical University School of Medicine, Japan \\ ${ }^{3}$ Biology, Department of Liberal Arts and Sciences Center for Medical Education, Sapporo Medical University, Japan \\ Correspondence should be addressed to Masashi Idogawa; idogawa@sapmed.ac.jp and Takashi Tokino; tokino@sapmed.ac.jp \\ Received 24 July 2019; Accepted 24 July 2019; Published 7 August 2019 \\ Copyright @ 2019 Masashi Idogawa et al. This is an open access article distributed under the Creative Commons Attribution \\ License, which permits unrestricted use, distribution, and reproduction in any medium, provided the original work is \\ properly cited.
}

In the article titled "Prognostic Effect of Long Noncoding RNA NEAT1 Expression Depends on p53 Mutation Status in Cancer" [1], there was an error in the Results section. In the third paragraph, the sentence "Although total RNA was treated with oligo dT to select for polyadenylated mRNAs in the RNA-seq protocol used to obtain TCGA data, the NEAT1_2 sequence includes five consecutive Trepeats, with at least ten repeats (maximum: 17)" should be corrected to "Although total RNA was treated with oligo dT to select for polyadenylated mRNAs in the RNA-seq protocol used to obtain TCGA data, the NEAT1_2 sequence includes five consecutive A repeats, with at least ten repeats (maximum: 22)."

\section{References}

[1] M. Idogawa, H. Nakase, Y. Sasaki, and T. Tokino, "Prognostic effect of long noncoding RNA NEAT1 expression depends on p53 mutation status in cancer," Journal of Oncology, vol. 2019, Article ID 4368068, 7 pages, 2019. 


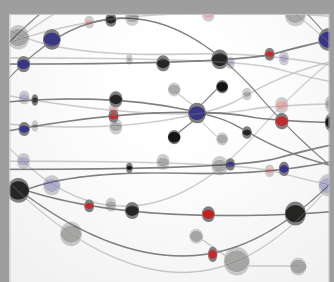

The Scientific World Journal
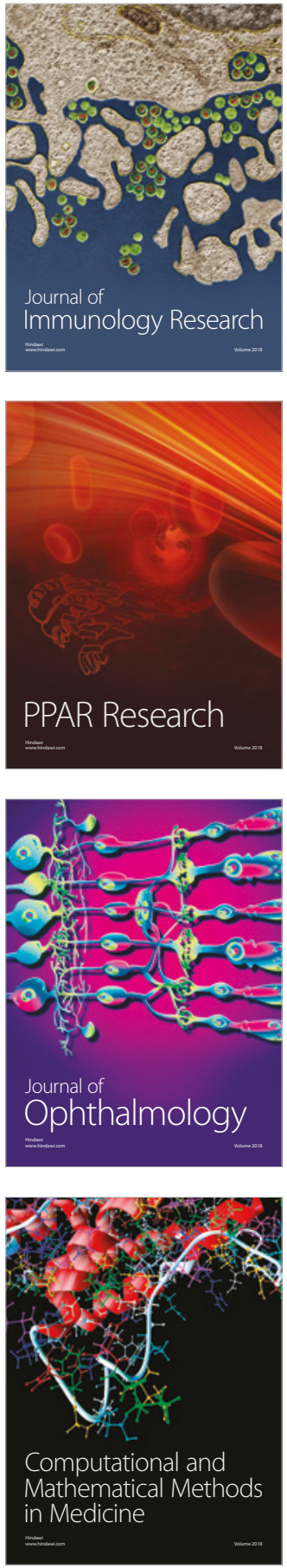

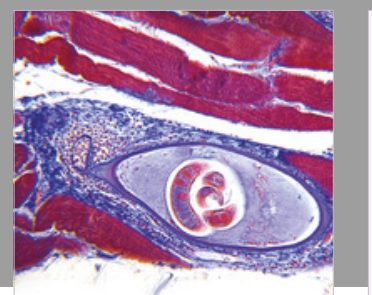

Gastroenterology Research and Practice

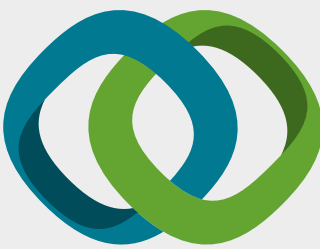

\section{Hindawi}

Submit your manuscripts at

www.hindawi.com
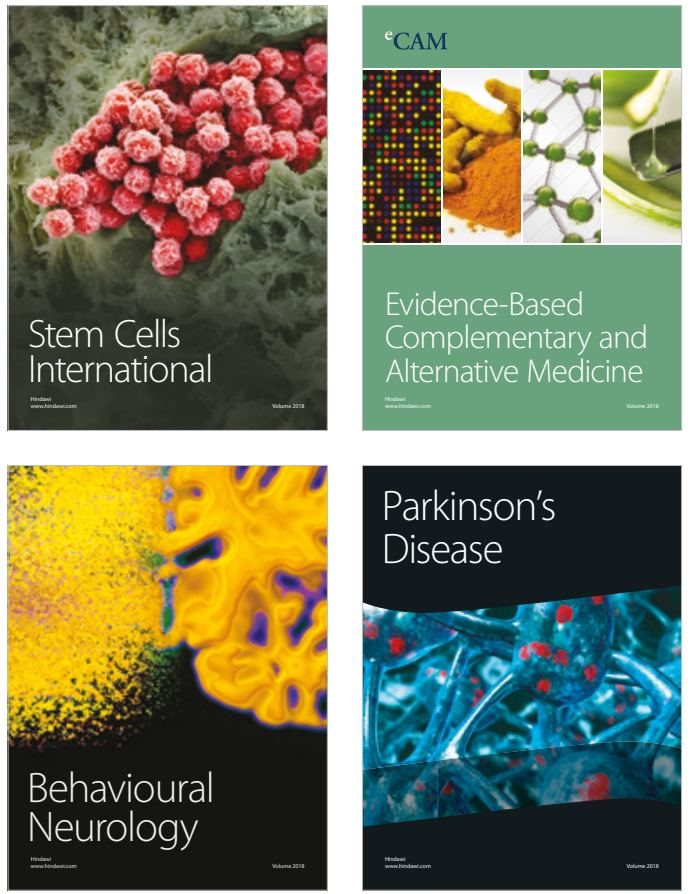

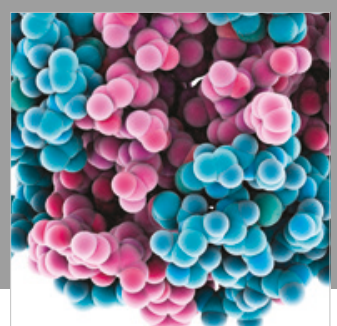

ournal of

Diabetes Research

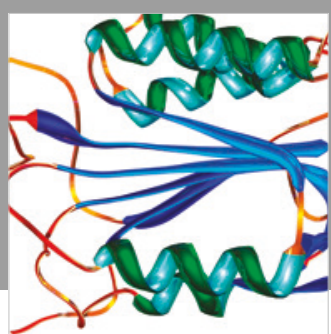

Disease Markers
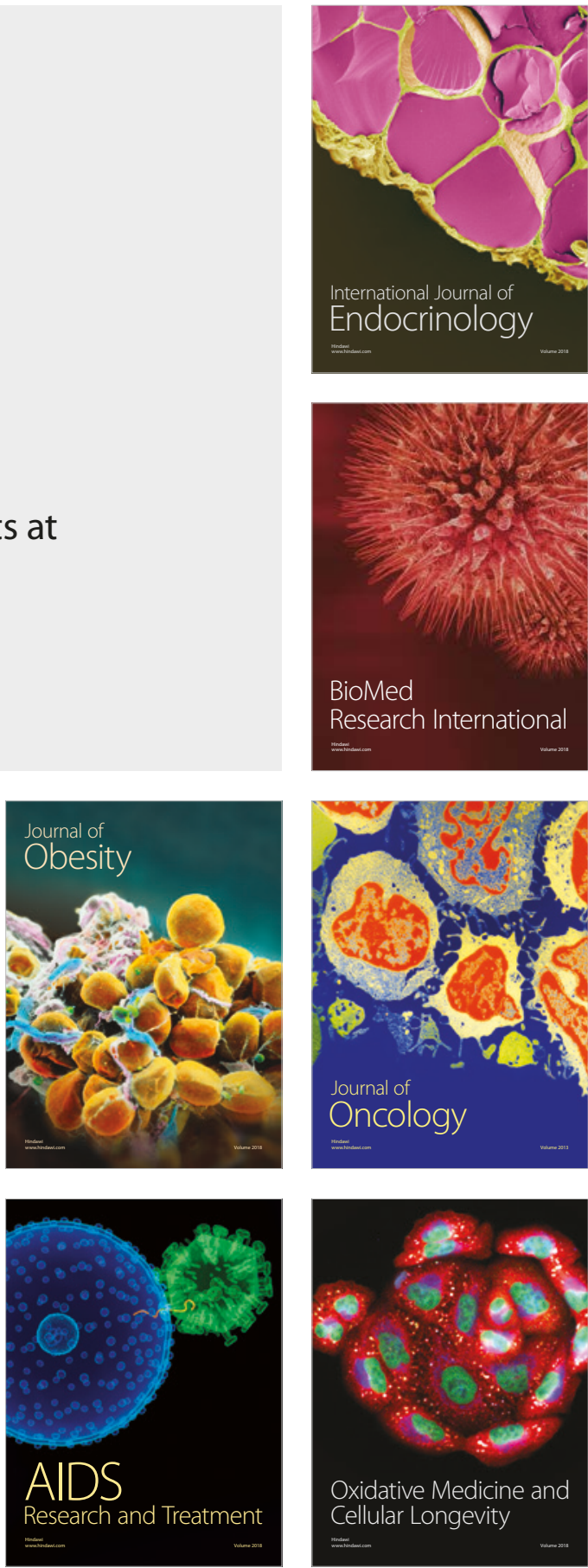